\title{
TRATAMENTO DE DADOS EM UMA PERSPECTIVA DA LEI GERAL DE PROTEÇÃO DE DADOS DURANTE A PANDEMIA DE COVID-19
}

\author{
DATA PROCESSING FROM A PERSPECTIVE OF THE GENERAL DATA PROTEC-TION LAW \\ DURING THE COVID-19 PANDEMIC
}

\begin{abstract}
Débora Manke Vieira
Instituto Ibero-americano de Compliance, Porto Alegre, RS, Brasil. E-mail: deboramanke@gmail.com

(iD https://orcid.org/0000-0003-0494-2639
\end{abstract}

\section{Fabrizio Bon Vecchio}

Universidade do Vale do Rio dos Sinos, Porto Alegre, RS, Brasil. E-mail: fbvecchio@hotmail.com

https://orcid.org/0000-0002-9519-2492

DOI: https://doi.org/10.46550/ilustracao.v1i1.5

Recebido em: 13.10 .2020

Aceito em: 21.11.2020

\begin{abstract}
Resumo: A COVID-19 e a tecnologia expandiram-se em velocidades assustadoras, implicando em um aumento expressivo de produçáo de dados. Este cenário, exige, portanto, a necessidade de serem instituídos mecanismos que possibilitem um grau de proteção adequado a estas informaçóes, de forma que o sujeito de direito possa deter conhecimento e controle sobre suas próprias informaçóes, que são expressão direta de sua personalidade. Apesar da faceta de insumo essencial ao desenvolvimento das atividades econômicas e administrativas, os dados pessoais são uma extensão da personalidade humana, motivadas pelas complexas ferramentas de coleta, armazenamento e processamento de dados, que individualmente, podem não ser nocivos, mas quando cruzados com outras informações podem adquirir um novo valor, e também potencial de controle sobre seus emissores.
\end{abstract}

Palavras-chave: Lei Geral de Proteção de Dados. COVID-19. Compartilhamento de Dados Pessoais. Saúde Pública.

\begin{abstract}
COVID-19 and technology expanded at the same rate, resulting in a significant increase in data production. This scenario, therefore, requires the need to establish mechanisms that enable an adequate degree of protection to this information, so that the subject of law can have knowledge and control over his own information, which is a direct expression of his personality. Despite the facet of input essential to the development of economic and administrative activities, personal data is an extension of the human personality, motivated by the complex data collection, storage and processing tools, which individually, may not be harmful, but when crossed with others information can acquire new value, as well as the potential for control over its issuers.
\end{abstract}

Keywords: General Data Protection Law. COVID-19. Sharing of Personal Data. Public Health. 


\section{Introdução}

Quando surgiram as primeiras geraçóes legislativas que tratavam da proteção de dados, percebeu-se que não estavam propriamente ligadas à ideia de privacidade, mas a mero fenômeno computacional. O marco inicial de uma dimensão positiva de proteção foi evocado pela Corte Constitucional Alemã - conferindo ao indivíduo o poder de decisão pela utilização e divulgação de seus dados pessoais, fato inédito até aquela decisão.

O enfrentamento da pandemia de COVID-19 que avançou rapidamente em uma escala global nunca antes experimentada, despertou uma preocupação latente com questóes mais complexas que a simples atividade da gestão de saúde. Em momentos de crise normalmente se aceitam restrições a direitos e garantias em troca de maior segurança, os valores são relativizados em nome de um bem maior, neste caso a vida.

Um exemplo emblemático ocorreu após o atentado de 11 de setembro de 2001, onde o Congresso americano obteve apoio para o Uniting and Strengthening America by Providing Appropriate ou apenas "Patriot Act", que permitiu as autoridades norte americanas o livre acesso e a permissão para quebra do sigilo telefônico, entre outras medidas. Situaçôes como esta demonstram que atitudes invasivas e autoritárias em períodos de grave crise, por falta de normas preestabelecidas, podem tornar-se medidas permanentes; diversos países estão se utilizando do atual cenário para coleta de dados pessoais - este é o objetivo dessa pesquisa, analisar situaçóes de urgência que suprimiram direitos individuais durante esse grave período, e de também perseguir as experiências de outros países que reconheceram a sensibilidade dos dados relacionados à saúde dos cidadãos.

Antes da entrada em vigor da Lei Geral da Proteção de Dados, o Brasil vivenciou uma situação similar quando o Supremo Tribunal Federal afastou a Medida Provisória 954 que permitia o compartilhamento de dados pessoais - dados de geolocalização - mantidos por empresas telefônicas com o IBGE (Instituto Brasileiro de Geografia e Estatística). ${ }^{1}$ Essa construção teórica, demonstra a influência europeia do Tribunal Constitucional Alemão e dá aparência de que a lei brasileira terá uma eficácia plena.

Sem dúvida alguma devemos proteger a saúde pública, e isto, por si só, autoriza a exceção à regra de consentimento - mas deve haver justificativa que autorize essa quebra. Reconhecemos que somente é possível conter o avanço de doenças coletando um maior número de informações possíveis de modo assertivo, utilizando-se de recursos de gestão da saúde pública. Porém, até quando essas empresas e órgãos governamentais irão armazenar esses dados? Há o risco de serem utilizados para fins imorais ou ilícitos e até mesmo de comercialização? A tecnologia empregada democraticamente durante a disseminação do coranavírus, não poderá ser revertida.

Utilizando uma revisão bibliográfica por meio de doutrinas nacionais e internacionais, buscaremos as experiências em países que já vivenciaram graves crises de saúde pública e faremos

1 "As açóes foram propostas pelo Conselho Federal da Ordem dos Advogados do Brasil - OAB (ADI 6387), pelo Partido da Social Democracia Brasileira - PSDB (ADI 6388), pelo Partido Socialista Brasileiro - PSB (ADI 6389), pelo Partido Socialismo e Liberdade - PSOL (ADI 6390) e pelo Partido Comunista do Brasil (ADI 6393). Entre outros argumentos, eles alegam que a MP, ao obrigar as empresas de telefonia fixa e móvel a disponibilizar ao IBGE a relaçáo dos nomes, dos números de telefone e dos endereços de seus consumidores, pessoas físicas ou jurídicas, viola os dispositivos da Constituição Federal que asseguram a dignidade da pessoa humana, a inviolabilidade da intimidade, da vida privada, da honra e da imagem das pessoas e o sigilo dos dados." (SUPREMO TRIBUNAL FEDERAL. STF suspende compartilhamento de dados de usuários de telefônicas com IBGE. Disponível em: http://www.stf.jus.br/portal/cms/verNoticiaDetalhe.asp?idConteudo=442902. Acesso em 22 nov, 2020). 
uma comparação com a Lei Geral de Proteção de Dados.

2 Lei Geral de Proteção de Dados: como recepcionamos a legislaçáo em meio a crise sanitária de COVID-19?

Com a vigência da Lei Geral de Proteção, em meio a crise sanitária de COVID-19, a necessidade de guarda da saúde e da privacidade dos usuários náo nos parece ter sido uma prioridade. Logo nos primeiros meses, a permissão para o acesso de dados pessoais - como a geolocalização dos aparelhos celulares para fins de controle de circulação da "rota do vírus" -, já demonstrou que algumas medidas, aparentemente nocivas e necessárias para preservação dos cidadãos, se mostraram inconstitucionais e violadoras da novel legislação.

Na Lei Geral de Proteçáo de Dados parte-se da ideia de que todo dado pessoal tem importância e valor. Por essa razáo se adotou o conceito amplo de dado pessoal, assim como estabelecido no Regulamento Europeu - General Data Protection Regulation ${ }^{2}$-, sendo ele definido como informação relacionada a pessoa natural identificada ou identificável. Dados que pareçam não ser relevantes em um momento, ou que não façam referência direta a alguém, uma vez transferidos, cruzados ou organizados, podem resultar em dados bastante específicos sobre determinada pessoa, trazendo informaçóes inclusive de caráter sensível sobre ela, conforme já observou o Bundesverfassungsgericht (Tribunal Constitucional Federal Alemão) no emblemático julgamento sobre a lei do censo de $1983 .^{3}$

André Lemos e Daniel Marques inventaram diferentes iniciativas de vigilância a partir dos dados produzidos por diferentes centros de pesquisa, como Data Privacy BR, InternetLab, ITS Rio, Programmably City e Ada Lovelace Institute, agrupando-as da seguinte maneira: (a) Geolocalização com mapeamento de fluxo e deslocamento a partir de dados das operadoras de celular, gerando mapas de calor e índices de isolamento urbano; (b) Contact Tracing, uso de bluetooth para identificar indivíduos que tiveram contato com pessoas contaminadas ou com sintomas; (c) Symptom Tracking, aplicativos para monitoramento de sintomas; (d) Drones, para monitorar e ajudar no cumprimento e reforço do isolamento social, sendo usado inclusive para dispersar aglomeraçóes; (e) Pulseiras (tipo Fit Bit) para monitoramento; (f) Câmeras de reconhecimento facial e; (g) Câmeras térmicas para identificar corpos febris. ${ }^{4}$

Quanto à noção de que a utilização dessas tecnologias poderia ser irreversível e prejudicial à privacidade, Guilherme Ornelas Monteiro já havia feito apontamentos quanto aos danos e a sensação de proteção garantida pelo ente governamental:

$\mathrm{Na}$ prática, não percebem como sua privacidade está sendo violada a partir de pequenos atos de coleta de informações que, vistos por si só, podem parecer inofensivos, mas que em seu conjunto acabam se tornando um poderoso instrumento de influenciar e moldar comportamentos. As pessoas estão inclinadas

2 A disposição brasileira segue o previsto no General Data Protection Regulation: "Artigo 4o. Definiçóes. Para efeitos do presente regulamento, entende-se por: $<<$ Dados pessoais $>>$, informaçấo relativa a uma pessoa singular identificada ou identificável (<<titular dos dados>>); é considerada identificável uma pessoa singular que possa ser identificada, direta ou indiretamente, em especial por referência a um identificador, como por exemplo um nome, um número de identificaçáo, dados de localização, identificadores por via eletrônica ou a um ou mais elementos específicos da identidade física, fisiológica, genética, mental, econômica, cultural ou social dessa pessoa singular;".

3 "Um dado em si insignificante pode adquirir um novo valor: desse modo, não existem mais dados insignificantes no contexto do processamento eletrônico de dados" (MARTINS, Leonardo. Cinquenta anos de Jurisprudência do Tribunal Constitucional Federal Alemão. Montevidéu: Fundação Konrad Adenauer, 2005, p. 244-245).

4 LEMOS, André; MARQUES, Daniel. Vigilância Guiada por Dados, Privacidade e Covid-19. Ensaios: Dossiê Covid-19. Disponível em: http://www.lab404.ufba.br/vigilanciaguiada-por-dados-privacidade-e-covid-19/. Acesso em 16 nov. 2020. 
a fornecer seus dados quando confrontadas com propostas, pois não possuem compreensão completa das consequências que podem ser geradas a partir de seu fornecimento, isto é, não há como valorar a privacidade sem conhecer as irradiaçóes do tratamento dos dados. ${ }^{5}$

A importância da coleta dessas informaçôes permite a adoção de diagnósticos para contenção da doença, cercar perímetros onde infectados estão em contato com a população, estimular que se mantenham em isolamento social - como a OMS recomenda - e, até mesmo, enviar mensagens de SMS para os telefones celulares geolocalizados ${ }^{6}$ - medida da Defesa Civil Nacional, que permitiu aos interessados receber avisos por SMS após enviar uma mensagem para o número da entidade alertando a situação pandêmica e a troca do sistema de bandeiras.

$\mathrm{O}$ direito à privacidade, quando não observado, pode ser acessado por terceiros mal intencionados e, até mesmo, por empresas seguradoras de saúde, violando a esfera privada e causando abusividade na cobrança de mensalidades de planos. Nesse sentido, Anderson Schreiber afirma que, "em uma sociedade caracterizada pelo constante intercâmbio de informaçóes, o direito à privacidade deve se propor a algo mais que àquela finalidade inicial, restrita à proteção da vida íntima, devendo abarcar também o direito do indivíduo de manter o controle sobre seus dados pessoais".

Outro estudo analisado foi o de Chen Qiang, sobre como envolver os cidadãos durante a pandemia por meio de mídias sociais. Apresentou uma outra visão sobre o envolvimento ativo dos cidadáos nas pautas públicas, empoderando os sujeitos como participantes e tomadores de decisóes e aumentando as relaçóes de confiança entre os Estados e o povo. Há relatos de uso de mídias sociais em emergências, nem sempre diretamente ligadas à temática de saúde e seu devido controle. Os autores destacam que o Reino Unido usou a rede social Twitter para o monitoramento de hashtags e menções para auxílio na identificação de suspeitos durante ataques terroristas ocorridos em 2011. Na Indonésia, a mesma rede social foi utilizada para a elaboraçáo de estratégias de alerta à população durante o tsunami de 2012, aprimorando a prestação de serviços do Estado. É possível verificar que o uso de mídias sociais por parte dos governos quando em favor de estratégias públicas são validadas para auxiliar em emergências. ${ }^{8}$

Os Estados Unidos e a China trouxeram práticas de fiscalização invasivas, como o uso de drones e câmeras de segurança para monitorar os níveis de isolamento social, infringindo o direito à privacidade, afinal, tais dispositivos não possibilitam que o usuário capturado permita a exploração de sua imagem para compartilhamento. Dessa forma, inegavelmente, os Estados, ao conter o aumento de casos de coronavírus, vêm adotando tecnologias questionáveis quando permitem o acesso irrestrito de informaçôes pessoais. ${ }^{9}$

Diversos países estão se utilizando de tecnologias públicas e privadas para coletar

5 MONTEIRO, Guilherme Ornelas. Proteção de Dados Pessoais: uma análise dos efeitos da pandemia da COVID-19 na proteção dos dados. Revista Caderno Virtual, 2020, p. 455. Disponível em: https://portaldeperiodicos.idp.edu.br/ cadernovirtual/article/view/4849. Acesso em 21 nov. 2020.

6 MODESTO, Jéssica Andrade; JUNIOR, Marcos Ehrhardt. Danos colaterais em tempos de pandemia: preocupaçóes quanto ao uso dos dados pessoais no combate a COVID-19. REDES - Revista Eletrônica Direito e Sociedade, Canoas, v. 8, n. 2, 2020, p. 145.

7 SCHREIBER, Anderson. Direitos da personalidade. 3. Ed. São Paulo: Atlas, 2014, p. 137.

8 QIANG, Chen. MIN, Chen; ZHANG, Wei; WANG, Ge; MA, Xiaoyue; EVANS, Richard. Unpacking the black box: How to promote citizen engagement through government social media during the COVID-19 crisis. Comput Human Behav. Disponível em: https://pubmed.ncbi.nlm.nih.gov/32292239/. Acesso em 17 nov. 2020.

9 BIONI, Bruno Ricardo; ZANATTA, Rafael; RIELLI, Mariana; VERGILI, Gabriela; FAVARO, Iasmine. Os dados e o virus: Pandemia, proteção de dados e democracia. São Paulo: Reticências Creative Design Studio, 2020. 
informações de maneira descentralizada e difusa, atuação que Bruce Schneier chamou de "little brothers", que significa utilizar-se de "dispositivos que se alimentam das interaçóes online e offline dos indivíduos e que geram um volume imenso e valioso de informaçôes pessoais, inclusive aquelas relativas à saúde". ${ }^{10}$

A fiscalização massiva deve ser a medida necessária para averiguar quais empresas coletam dados sensíveis, onde armazenam informaçóes íntimas daquele usuário e, percebendo a abusividade, passe a descartar na tentativa de eximir-se da responsabilidade:

Em momento que a telemedicina passa a vigorar no Brasil para atender pacientes em isolamento, em que as plataformas digitais passam a coletar indiscriminadamente dados de saúde (portanto sensíveis) das pessoas, sem ao menos terem passados por testes de segurança oficiais validando suas defesas contra invasóes digitais, tornase essencial o reforço pela aplicação da LGPD inclusive para averiguar que essas empresas realizem a exclusão dos dados pós-pandemia. ${ }^{11}$

Vale lembrar que, de acordo com o artigo 13 da Lei Geral de Proteção de Dados, na realização de estudos em saúde, os órgãos de pesquisa poderão ter acesso a bases de dados pessoais, que serão tratados dentro do órgão estritamente para a finalidade de realização de estudos e pesquisas, sendo mantidos em ambiente controlado e seguro, conforme práticas de segurança previstas em regulamento específico e que incluam, sempre que possível, a anonimização ou pseudonimizaçáo dos dados ${ }^{12}$, bem como considerem os devidos padróes éticos relacionados a estudos e pesquisas. A divulgação dos resultados em nenhuma hipótese deverá revelar dados pessoais. ${ }^{13}$

Outra possibilidade autorizativa do tratamento de dados está presente quando for necessário para a execuçáo de contrato ou de procedimentos preliminares relacionados a contrato do qual seja parte o titular, a pedido do titular dos dados. A disposiçáo em questão é mais ampla do que aquela prevista no art. 11, II, d, da Lei Geral de Proteção de Dados, podendo o agente tratar, sem consentimento, os dados que são necessários para a contratação, bastando que o titular seja parte ou esteja em tratativas para um contrato. É possível trabalhar aqui dois exemplos: (1) nas situaçôes em que o titular adquire produtos ou serviços para entregá-los será preciso conhecer nome completo, endereço e outras informaçóes do contrato do consumidor e (2) levantamentos realizados por instituições financeiras em relação a determinada pessoa, anteriormente à concessão de crédito a ela. ${ }^{14}$

10 ARAÚJO, Priscila Maria Menezes de; BANDEIRA, Natalia Ferreira Freitas. Na pandemia, é possivel flexibilizar as balizas da proteção de dados pessoais? Disponível em: https://www.jota.info/opiniao-e-analise/artigos/na-pandemia-e-possielflexibilizar-as-balizas-da-protecao-de-dados-pessoais-01042020. Acesso em 17 nov. 2020.

11 MONTEIRO, Guilherme Ornelas. Proteção de Dados Pessoais: uma análise dos efeitos da pandemia da COVID-19 na proteção dos dados. Revista Caderno Virtual, 2020, p. 467. Disponível em: https:// portaldeperiodicos.idp.edu.br/cadernovirtual/article/view/4849. Acesso em 21 nov. 2020.

12 Art. $13, \$ 4^{\circ}$. Para os efeitos deste artigo, a pseudonimizaçáo é o tratamento por meio do qual um dado perde a possibilidade de associaçáo, direta ou indireta, a um indivíduo, senão pelo uso de informação adicional mantida separadamente pelo controlador em ambiente controlado e seguro.

13 TEFFÉ, Chiara Spadaccini de; VIOLA, Mario. Tratamento de dados pessoais na LGPD: estudo sobre as bases legais. Civilistica.com, a.9, n. 1, 2020, p. 24.

14 No entanto, o profiling dos interesses e preferências de um indivíduo com base nos itens adquiridos não é necessário para a execução do contrato e o responsável pelo tratamento não pode confiar nessa base legal como referência para esse processamento. Mesmo que esse tipo de publicidade direcionada seja uma parte útil do relacionamento com o cliente e seja uma parte necessária do modelo de negócios desse fornecedor, não é necessário para que o contrato seja automaticamente ilegal, mas que precisa procurar uma base legal diferente e outras salvaguardas. (ICO - Information Comissioner's Office. What is the 'legitimate interests' basis? Disponível em: <https://ico.org.uk/for-organisations/guide-to-data-protection/ guide-to-the-general-data-protection-regulation-gdpr/legitimate-interests/what-is-the-legitimate-interests-basis/\#three_ part_test>. Acesso em 19 nov. 2020). 
É de interesse coletivo a utilização da tecnologia como estratégia de contenção do vírus, afinal, as pandemias mundiais mais letais ocorreram em períodos em que não se contava com a internet como aliada. Como toda tecnologia expóe seus riscos e, em meio a uma situação anômala e de urgência, não poderia ser diferente. O que precisamos levar como lição desse período é que não devemos acreditar que apenas o legislador seja responsável pela integração e solução de todas as situaçôes de coleta indevida de dados pessoais: devemos abandonar os discursos prontos e contribuir para que medidas desesperadas não se tornem violadoras de direitos fundamentais.

\section{3 É lícita a coleta de dados sensíveis para fins de saúde coletiva?}

O legítimo interesse é hipótese legal que visa a possibilitar tratamentos de dados importantes, vinculados ao escopo de atividades praticadas pelo controlador, e que encontrem justificativa legítima. Diante da flexibilidade dessa base legal, as expectativas do titular dos dados têm peso especialmente relevante para sua aplicação, devendo ser consideradas também a finalidade, a necessidade e a proporcionalidade da utilizaçáo dos dados. Quanto mais invasivo, inesperado ou genérico for o tratamento, menor será a probabilidade de que seja reconhecido o legítimo interesse. ${ }^{15}$

A própria Lei Geral de Proteção de Dados, em seu art. 10, caput e inciso I, fomenta a necessidade de perquirir a motivação do controlador, se ela contraria dispositivos legais, se está presente alguma vantagem que não seja puramente na contenção da pandemia. ${ }^{16}$ Todos os cuidados devem ser debatidos antes da permissão ao uso desenfreado dos dados usuários; sobretudo, quando há uma crise sanitária em vigor, pois o legítimo interesse pode ser facilmente ludibriado por controladores.

Situação comum é a possibilidade de utilizar esses dados como tutela da proteção à vida e manutenção da incolumidade física do titular em situaçôes excepcionais; "tanto a proteção da vida quanto a tutela da saúde, precisam ocorrer em situaçóes de risco imediato, não podendo ser utilizadas como forma preventiva, por exemplo, aumentar o prêmio de seguros ou planos de saúde privados" ${ }^{17}$. Mas a obtenção dos dados de geolocalização de smartphones com a finalidade de localização de pessoas sequestradas, desaparecidas em escombros e para contenção do avanço

15 Como exemplos de legítima expectativa de tratamento dados, vale trazer o seguinte exemplo: "An individual uploads their $\mathrm{CV}$ to a jobs board website. A recruitment agency accessesthe CV and thinks that theindividual may have the skills that two of its clients are looking for and wants to pass the CV to those companies. It is likely in this situation that the lawful basis for processing for the recruitment agency and their clientsis legitimate interests. The individual has made their CV available on a job board website for the express reason of employers being able to access this data. They have not given specific consent for identified data controllers, but they would clearly expect that recruitment agencies would access the CV and share with it their clients, indeed this is likely to be the individual's intention. As such, the legitimate interest of the recruitment agencies and their clients to fill vacancies would not be overridden by any interests or rights of the individual. In fact, those legitimate interests arelikely to align with the interests of the individual in circulating their CV in order to find a job". Outro exemplo a se mencionar seria: "An individual creates a profile on a social networking website designed specifically for professional networking. There is a specific option to select a function to let recruiters know that the individual is open to job opportunities. If the individual chooses to select that option, they would clearly expectthose who view their profile might use their contact details for recruitment purposes and legitimate interests may be available (subject to compliance with other legal requirements, and PECR in particular). However, if they choose not to select that option, it is not reasonable to assume such an expectation. The individual's interests in maintaining control over their data - particularly in the context of the PECR requirement for specific consent to receive unsolicited marketing messages -overrides any legitimate interests of a recruitment agency in promoting its services to potential candidates". (ICO - Information Comissioner's Office. Disponível em: <https://ico.org.uk/for-organisations/guide-to-data-protection/ guide-to-the-general-data-protection-regulation-gdpr/legitimate-interests/what-is-the-legitimate-interests-basis/\#three_ part_test>. Acesso em 19 nov. 2020).

16 BIONI, Bruno. Proteção de dados pessoais: a função e os limites do consentimento. 2. Ed. Rio de Janeiro: Forense, 2020, p. 237.

17 OLIVEIRA, Ricardo; COTS, Mário (Coord.). O legítimo interesse e a LGPDP: Lei Geral de Proteção de Dados Pessoais. 1. Ed. São Paulo: Thomson Reuters Brasil, 2020, p. 54. 
da crise sanitária causada pela COVID-19 é comum.

O caso do mapeamento epidemiológico certamente é o uso mais polêmico da tecnologia nesse período. O governo criou um mapa epidemiológico capaz de mostrar a localização de pessoas infectadas, alertando aqueles indivíduos, então preservados do vírus, que evitassem determinados locais, causando estigma e gerando fortes ondas de ódio e preconceito. ${ }^{18}$

A redação dada pela Lei Geral de Proteção de Dados acrescentou "serviços de saúde" à redação original do inciso VIII do artigo 7o , causando certa insegurança jurídica. A problemática, nesse ponto, é que, via de regra, os profissionais da área da saúde estão sujeitos a rigorosos códigos de ética que os obrigam ao sigilo, enquanto nas demais áreas nem sempre isso se verifica ${ }^{19}$ - aqui poderíamos enaltecer a importância do compliance na área de proteção de dados, mas o estudo não pretende adentrar nessa discussão.

Nessa direção, podemos determinar se um dado é sensível ou não através da verificação do contexto de seu emprego, além do confronto com as demais informaçóes disponíveis e a expressão máxima de seu tratamento servir como instrumento de estigmatização. ${ }^{20}$ Como destaca doutrina: “(...) deve-se admitir que certos dados, ainda que não tenham, a princípio, essa natureza especial, venham a ser considerados como tal, a depender do uso que deles é feito no tratamento de dados". ${ }^{21}$ Em diversos países da União Europeia tem sido preconizado também o "consentimento ativo", que seria a vedação da obtenção do consentimento de forma implícita, pela mera inação do titular dos dados em não se opor ao tratamento, sem engajamento direto do titular, por assim dizer. ${ }^{22}$

É necessário, portanto, auditar se os regramentos previstos na Lei Geral de Proteção de Dados estão sendo respeitados; somente com este levantamento é que será possível enfrentar o combate da crise sanitária. Segundo coloca Doneda, a normativa brasileira de proteção de dados convive bem com regimes complexos de autorizações e limitações específicas para uso de dados conforme os atributos presentes, sendo capaz de proporcionar, ao mesmo tempo, uma utilização efetiva e segura dos dados em tempos de pandemia. Assim, os tratamentos deverão ser pontuais e somente poderão ocorrer uma vez justificados adequadamente. Afinal, o tratamento deve respeitar garantias e direitos individuais, sendo feito dentro de limites temporais e finalísticos estritamente para a contenção da pandemia, sem qualquer outro interesse nessa medida permissiva. ${ }^{23}$

Os dados pessoais na saúde cumprem, sem dúvida, outra função que vai além da proteção da privacidade - devem orientar o uso e a disponibilização das informaçôes enquanto bem jurídico tutelado, de forma a garantir, a satisfação de necessidades coletivas. Essa reinterpretação do direito à privacidade e à informação na saúde requer uma regulamentação que articule proteção da privacidade e promoção do acesso à informação no mesmo nível que as necessidades comuns

18 BENTO, Rafael Tedrus; ROSSI, Vinicius Medeiros. Proteção de dados na crise do coronavírus. Disponível em: https://www. migalhas.com.br/depeso/324004/protecao-de-dados-na-crise-do-coronavirus. Acesso em 22 nov. 2020.

19 Ibidem, p. 55.

20 KONDER, Carlos Nelson. O tratamento de dados sensíveis à luz da Lei 13.709/2018. TEPEDINO, Gustavo; FRAZÃO, Ana; OLIVA, Milena Donato. Lei Geral de Proteção de Dados Pessoais e suas repercussóes no Direito Brasileiro. São Paulo: Revista dos Tribunais, 2019, p. 460.

21 MULHOLLAND, Caitlín. Dados pessoais sensíveis e consentimento na Lei Geral de Proteção de Dados Pessoais. Revista do Advogado, n. 144, nov. 2019, p. 49.

22 CAROLAN, Eoin. The continuing problems with online consent under the EU's emerging data protection principles. Computer Law and Security Review, 2016. Disponível em: https://www.sciencedirect.com/science/article/abs/pii/ S0267364916300322. Acesso em 19 nov. 2020.

23 DONEDA, Danilo. A proteção de dados em tempos de coronavírus. Disponível em: https://www.jota.info/opiniao-e-analise/ artigos/a-protecao-de-dados-em-tempos-de-coronavirus-25032020. Acesso em 21 nov. 2020. 
e as possibilidades tecnológicas disponíveis. ${ }^{24}$

A Lei Federal no 8.080/1990, que regulamenta o direito à saúde, inclui o direito à informação do cidadão e o dever do Estado de fundamentar suas políticas e ações em informações sanitárias e evidências científicas, legitimando a coleta e uso de informaçóes pessoais. E não apenas isso deve ser o fator determinante:

Para além da lei, a expectativa geral da população é que a informação em saúde permitauma melhor qualidade devidae redução de riscosaoadoecimento. Contudo, observa-se que há certa resistência dos indivíduos em fornecer informaçôes que possam resultar em algum tipo de controle de seu comportamento, bem como as motivaçôes da coleta alteram sua invocação à privacidade. Os dados pessoais na saúde cumprem, indubitavelmente, uma outra função que vai além da proteção da privacidade em prol da produção de um bem comum. $\mathrm{O}$ interesse coletivo é intrínseco à compreensão de bem comum na saúde, e determina os valores e parâmetros que devem orientar o uso e a disponibilização dos dados pessoais enquanto bem jurídico tutelado, de forma a garantir, preponderantemente, a satisfaçâo de necessidades coletivas. ${ }^{25}$

Todos esses direitos já citados representam pilares da democracia moderna e exigem ampla participaçáo social para sua efetividade. O "capitalismo de vigilância”, com múltiplos interesses mercadológicos e pessoais em jogo, desafia a formulação de leis e políticas informativas, com base em dados pessoais, garantindo-se a dimensão pública não exclusivamente sob a proteção estatal, mas em promoção dos deveres do poder público na proteção da privacidade e promoção ao acesso às informaçôes. ${ }^{26}$

Muito comuns foram os casos de distúrbios mentais causados pelo isolamento social. A população sensibilizada pela crescente de casos de infecção, os números elevados de mortalidade diária, as disseminaçóes de fake news de métodos terapêuticos e possíveis causas da origem do vírus, contribuíram para a construção de pessoas amedrontadas que passaram a seguir e acreditar que o Estado iria solver todos os problemas. Guilherme Ornellas Monteiro, no mesmo sentido, observa que:

O combate à pandemia serve de pretexto para que governos criem políticas de recolhimento de dados pessoais de modo a induzir que pessoas assentem pelo processamento desses dados sem que tenham uma real percepção dos desarraigamentos da provisão destes, isso porque estariam essas pessoas anestesiadas pela promessa de salvaguarda sanitária pelo Estado. Em tempos de calamidade pública, as pessoas estão suscetíveis e fragilizadas para dispor dessas informaçóes sem questionar os seus reflexos: se tornam resignadas. ${ }^{27}$

Todas as políticas e medidas que visem a imediata proteção da saúde coletiva devem ser reavaliadas, debatidas e elevadas a um nível de proteção forte o suficiente para coletar dados regionais, onde, quando explorados, preservem a intimidade humana e, ao mesmo tempo, possibilitem uma “invasão contida” em prol da saúde. Afinal, se permitirmos pequenas violações

24 VENTURA, Miriam; COELI, Claúdia Medina. Para além da privacidade: direito à informação na saúde, proteção de dados pessoais e governança. Caderno de Saúde Pública, 2018. Disponível em: https://www.scielo.br/pdf/csp/v34n7/16784464-csp-34-07-e00106818.pdf. doi: https:// doi.org/10.1590/0102-311x00106818. Acesso em 22 nov. 2020.

25 Ibidem.

26 KEINERT, Tania Margarete Mezzomo; CORTIZO, Carlos Tato. Dimensôes da privacidade das informaçôes em saúde. Cadernos de Saúde Pública, 2018. Disponível em: https://www.scielosp.org/pdf/csp/2018.v34n7/e00039417. Acesso em 22 nov. 2020.

27 MONTEIRO, Guilherme Ornelas. Proteção de Dados Pessoais: uma análise dos efeitos da pandemia da COVID-19 na proteção dos dados. Revista Caderno Virtual, 2020, p. 457. 
aos dados, invariavelmente, conseguiremos reverter a situação no futuro.

\section{Consideraçóes finais}

Desde março de 2020 estamos vivenciando, de forma intensa, a pandemia de COVID-19 em nosso país. Com isso, observamos que, globalmente, a exploração de dados pessoais para o combate à doença vem buscando assegurar o monitoramento e o tratamento de pessoas infectadas. Este monitoramento visa o cumprimento de medidas de isolamento social e de restrição à aglomeração de pessoas, a identificação de quem teve contato com pessoas infectadas, a identificação de regiôes de maior risco de infecção: ou seja, a tecnologia vem sendo largamente utilizada para estes atos, contudo sem qualquer aviso de permissáo anterior ao uso.

O tratamento de dados pessoais deve assegurar a proteção de direitos garantidos constitucionalmente, náo devendo ser colocado em conflito com a privacidade de seus titulares, com a tutela da vida ou até mesmo com a saúde coletiva. Afinal, não podemos hierarquizar as normas constitucionais, apenas fazer uma análise de pesos e contrapesos, compatibilizando a ideia de que a tecnologia deve interferir na saúde pública para contenção do vírus, mas diante de direitos colidentes, não é permitido um alto nível de sacrifícios. Isso significa que carecem ser observados parâmetros a fim de ser evitar lesôes aos direitos da personalidade, sem sobretudo, ignorar que açóes imediatas devem ser aplicadas no auxílio da antidisseminaçáo do vírus.

A Lei Geral de Proteção de Dados entrou em vigor no período pandêmico, portanto, é normal que apareçam conflitos de interesses e ameaças de violaçóes a direitos. Outra face, a presença de um ente regulador independente - como a Agência Nacional de Proteção de Dados - seria de extrema importância diante desse cenário mundial, pois somente um órgáo autônomo e imparcial seria capaz de fiscalizar o uso correto de dados, visando soluçôes definitivas. Dita conformação permitiria a elaboração de um diálogo com as operadoras de telecomunicaçóes para coleta dos dados estatísticos, do engajamento do Ministério da Saúde para a criação de normas setoriais e no incentivo de hackatons para a criação de dados abertos, preservando os princípios da Lei Geral de Proteção de Dados.

Precisamos, enquanto Estado de Direito, promover mecanismos de proteção às garantias individuais, que possam vir a ser ameaçadas por açôes tomadas com o intuito de salvaguardar outros direitos elementares da população, em nome da contenção do vírus. Não estamos fazendo um juízo depreciativo das medidas governamentais, afinal, o estudo limita-se ao dogma, a letra legislativa e a ressignificação de conceitos advindo da LGPD; mas é preciso deixar em evidência que políticas aplicadas sem um juízo preeminente de prevenção de danos, podem resultar em efeitos irreversíveis e extremamente danosos aos cidadãos.

\section{Referências}

ARAÚJO, Priscila Maria Menezes de; BANDEIRA, Natalia Ferreira Freitas. Na pandemia, é possivel flexibilizar as balizas da proteção de dados pessoais? Disponível em: https://www.jota. info/opiniao-e-analise/artigos/na-pandemia-e-possiel-flexibilizar-as-balizas-da-protecao-dedados-pessoais-01042020. Acesso em 17 nov. 2020.

BENTO, Rafael Tedrus; ROSSI, Vinicius Medeiros. Proteção de dados na crise do coronavírus. Disponível em: https://www.migalhas.com.br/depeso/324004/protecao-de-dados-na-crise-docoronavirus. Acesso em 22 nov. 2020. 
BIONI, Bruno Ricardo. Proteção de dados pessoais: a função e os limites do consentimento. 2. ed. Rio de Janeiro: Forense, 2019, Ebook. Disponível em: https://integrada.minhabiblioteca. com.br/books/9788530988777. Acesso em 19 nov. 2020.

BIONI, Bruno Ricardo; ZANATTA, Rafael; RIELLI, Mariana; VERGILI, Gabriela; FAVARO, Iasmine. Os dados e o vírus: Pandemia, proteção de dados e democracia. São Paulo: Reticências Creative Design Studio, 2020.

CAROLAN, Eoin. The continuing problems with online consent under the EU's emerging data protection principles. Computer Law and Security Review, 2016. Disponível em: https:// www.sciencedirect.com/science/article/abs/pii/S0267364916300322. Acesso em 19 nov. 2020.

DONEDA, Danilo. A proteção de dados em tempos de coronavirus. Disponível em: https://www. jota.info/opiniao-e-analise/artigos/a-protecao-de-dados-em-tempos-de-coronavirus- 25032020. Acesso em 21 nov. 2020.

ICO - Information Comissioner's Office. Disponível em: <https://ico.org.uk/fororganisations/guide-to-data-protection/guide-to-the-general-data-protection-regulation-gdpr/ legitimate-interests/what-is-the-legitimate-interests-basis/\#three_part_test>. Acesso em 19 nov. 2020 .

ICO - Information Comissioner's Office. What is the 'legitimate interests' basis? Disponivel em: <https://ico.org.uk/for-organisations/guide-to-data-protection/guide-to-the-general-dataprotection-regulation-gdpr/legitimate-interests/what-is-the-legitimate-interests-basis/\#three_ part_test>. Acesso em 19 nov. 2020.

KEINERT, Tania Margarete Mezzomo; CORTIZO, Carlos Tato. Dimensões da privacidade das informaçôes em saúde. Cadernos de Saúde Pública, 2018. Disponível em: https://www. scielosp.org/pdf/csp/2018.v34n7/e00039417. Acesso em 22 nov. 2020.

KONDER, Carlos Nelson. O tratamento de dados sensíveis à luz da Lei 13.709/2018. TEPEDINO, Gustavo; FRAZÃO, Ana; OLIVA, Milena Donato. Lei Geral de Proteção de Dados Pessoais e suas repercussóes no Direito Brasileiro. São Paulo: Revista dos Tribunais, 2019.

LEMOS, André; MARQUES, Daniel. Vigilância Guiada por Dados, Privacidade e Covid-19. Ensaios: Dossiê Covid-19. Disponível em: http://www.lab404.ufba.br/vigilanciaguiada-pordados-privacidade-e-covid-19/. Acesso em 16 nov. 2020.

MARTINS, Leonardo. Cinquenta anos de Jurisprudência do Tribunal Constitucional Federal Alemão. Montevidéu: Fundação Konrad Adenauer, 2005, p. 244-245. Disponível em: www. kas.de/wtf/doc/26200-1442-1-30.pdf. Acesso em 19 nov. 2020.

MODESTO, Jéssica Andrade; JUNIOR, Marcos Ehrhardt. Danos colaterais em tempos de pandemia: preocupaçóes quanto ao uso dos dados pessoais no combate a COVID-19. REDES - Revista Eletrônica Direito e Sociedade, Canoas, v. 8, n. 2, 2020, p. 145.

MONTEIRO, Guilherme Ornelas. Proteção de Dados Pessoais: uma análise dos efeitos da pandemia da COVID-19 na proteção dos dados. Revista Caderno Virtual, p. 446- 473, 2020. Disponível em: https://portaldeperiodicos.idp.edu.br/cadernovirtual/article/view/4849. Acesso em 21 nov. 2020.

MULHOLLAND, Caitlín. Dados pessoais sensíveis e consentimento na Lei Geral de Proteção 
de Dados Pessoais. Revista do Advogado, n. 144, p. 47-53, nov. 2019.

OLIVEIRA, Ricardo; COTS, Mário (Coord.). O legitimo interesse e a LGPDP: Lei Geral de Proteção de Dados Pessoais. 1. Ed. São Paulo: Thomson Reuters Brasil, 2020.

QIANG, Chen. MIN, Chen; ZHANG, Wei; WANG, Ge; MA, Xiaoyue; EVANS, Richard. Unpacking the black box: How to promote citizen engagement through government social media during the COVID-19 crisis. Comput Human Behav. Disponível em: https://pubmed. ncbi.nlm.nih.gov/32292239/. Acesso em 17 nov. 2020.

SCHREIBER, Anderson. Direitos da personalidade. 3. Ed. São Paulo: Atlas, 2014.

SUPREMO TRIBUNAL FEDERAL. STF suspende compartilhamento de dados de usuários de telefônicas com IBGE. Disponível em: http://www.stf.jus.br/portal/cms/verNoticiaDetalhe. asp?idConteudo=442902. Acesso em 22 nov, 2020.

TEFFÉ, Chiara Spadaccini de; VIOLA, Mario. Tratamento de dados pessoais na LGPD: estudo sobre as bases legais. Civilistica.com, Rio de Janeiro, a.9, n. 1, p. 1-38, 2020. Disponível em: http://civilistica.com/tratamento-de-dados-pessoais-na-lgpd/. Acesso em 20 nov. 2020.

VENTURA, Miriam; COELI, Claúdia Medina. Para além da privacidade: direito à informação na saúde, proteção de dados pessoais e governança. Caderno de Saúde Pública, 2018. Disponível em: https://www.scielo.br/pdf/csp/v34n7/1678-4464-csp-34-07-e00106818. pdf. Acesso em 22 nov. 2020. 